\title{
Fight against Suicide
}

\author{
doi: 10.3329/jemc.v5i1.21490
}

The term suicide originated from Latin word "Sui" (of oneself) and "caedere" (to kill). ${ }^{1}$ It was first used by British physician Sir Thomas Browne in 1642. In United Kingdom it is the third contributor to death after coronary heart disease and cancer. ${ }^{2}$ It is alarming that the rate of suicide is gradually increasing day by day among the teenage and young men and women. World Health Organization put attention for suicide prevention in national and international level. Higher rates of suicide are found in eastern and northern Europe and lower rates in Mediterranean countries; the rate is very low in Islamic countries ${ }^{2}$ due to religious constraint. In Bangladesh the suicide rates are increasing among teenage and young group. It is also reported that in Bangladesh the rates have been highest in Jhenaidah.

The epidemiology of suicide indicates that two-thirds of the depressive patients have suicidal ideation, but $11-17 \%$ (average 15\%) of depressive patients die by suicide. ${ }^{2-4}$ Researchers found that suicide rate is 3 times more in male than female $(M: F=3: 1)$; but the rate of parasuicide (deliberate self-harm) is 2 times more in female than male $(\mathrm{M}: \mathrm{F}=1: 2){ }^{2}$

It has been mentioned that there is a four-fold increase in death rates of patients over age 55 years having depressive disorders in western world. ${ }^{3}$ In one study in United States it was found that more than two-thirds of those who die by suicide have expressed previously about the idea of suicide. ${ }^{2}$ It was also found that risk of suicide is more in those persons who write suicide note or tear up the note after writing. ${ }^{2}$ Researchers found that people who have intentionally harmed themselves (deliberate self-harm) have a much increased risk of suicide later on. ${ }^{2}$ Patients may commit suicide during the treatment of depressive disorder when they begin to improve and regain energy needed for plan to carry out suicide. This is called paradoxical suicide.

The questions may arise why people commit suicide. The answers remain in the main two domains: A. Psychological causes and B. Social causes. Among the psychological causes the following conditions are included:
1. Personality disorder (30-50\%): This is predisposed to depressive illness and/or alcoholism.

2. Depressive disorder $(15 \%)$

3. Alcohol misuse (7\%) (More in old group)

4. Drug misuse

5. Schizophrenia (7\%)

6. Epilepsy $(7 \%)$

7. Chronic painful illness, eg, cancer

8. Widow, widower, separated, older and unmarried male

Among the social causes the following factors may be responsible:

1. Eve teasing

2. Sexual abuse

3. Problems in relationship with partner/breaking of affairs

4. Stressful life events

5. Social isolation

6. Unemployment

7. Poverty

8. Poor physical ill health

9. Students

10. Doctors

11. Immigrants

12. Farmers

13. Media coverage of suicide: Showing of fictional television program and films depicting suicide. ${ }^{2}$ Sometimes people copy methods of suicide that have received wide media attention.

14. Mass suicide among the members of special religious community, eg, 913 followers of temple cult died in Guyana in 1978 and 39 members of Heaven gate cult in California in $1997 .^{2}$ Recently in Mymensingh (Bangladesh) a group of people of same family committed mass suicide by jumping under the train.

15. Pack suicide: In this case dominant partner of love affair initiates the suicide. Suicide pacts have to be 
distinguished from cases where homicide is followed by suicide or where one person aids another person's suicide without intending to kill himself.

16. Previous suicide attempts: $40-60 \%$ of those who die by suicide have made previous attempts. ${ }^{5}$

For prevention of suicide we need multiple approaches. Among the suicide cases $65 \%$ suffered from depressive disorder and $15 \%$ were chronic alcoholics. ${ }^{5}$ Following measures will help to fight against suicide.

1. Family education about morality and sound religious knowledge and practice which help the children to make up their development of good adjustable personality.

2. Teaching the general practitioners about diagnosis and treatment of depressive disorders and other psychiatric disorders related to suicide.

3. Better and more available psychiatric services should be disseminated in the community.

4. Public awareness by campaigning to educate the people regarding suicide.

5. Restricting the means of suicide by reducing availability of methods of suicide.

6. Counseling services by crisis centers and 'Hotlines': Here people in despair are encouraged to contact a widely published telephone numbers. The help offered (befriending) is provided by nonprofessional volunteers who are trained to listen sympathetically and empathetically also.
7. Long term medication for psychiatric patients: Less toxic antidepressant drugs for treatment of depressive disorders reduce the risk of suicidal behaviors. Lithium prophylaxis (mood stabilizer) reduces the suicide rates of patient having bipolar mood disorder (both depression and mania/hypomania). Clozapine (antipsychotic) may reduce suicidal attempts by patients with schizophrenia and schizoaffective disorders. ${ }^{2}$

\section{Dewan AKM Abdur Rahim}

Professor, Department of Psychiatry

Enam Medical College, Savar, Dhaka

Email: emc_savar@yahoo.com

\section{References}

1. DK Illustrated Oxford Dictionary. New Delhi: Penguin Books India, 2006: 832

2. Suicide and deliberate self-harm. In: Gelder M, Harrison P, Crowen P (eds). Oxford textbook of psychiatry. $5^{\text {th }}$ edn. New Delhi: Oxford University Press, 2006: 407-428.

3. Mood disorders. Kaplan Hl, Sadock BJ, Grebb JA (eds). Kaplan and Sadock's synopsis of psychiatry. $7^{\text {th }}$ edn. New Delhi: Bl Waverly Pvt Ltd., 1994: 332-333.

4. Black D, Winokur G, Hasrallah A. Suicide in subtypes of major affective disorders. Archives of Gen Psych 1987; 44: 878-880.

5. Roy A. Self-destructive behavior. In: Hill P, Murray R, Thorley A (eds). Essentials of postgraduate psychiatry. $2^{\text {nd }}$ edn. G\&S London 1986: 445-460. 